\title{
Visual status in primary open-angle glaucoma: A hospital- based report from Nepal
}

Shakya-Vaidya S', Aryal UR², Grjibovski AM³ ${ }^{3}$ Krettek $A^{4}$

'Suraj Shakya-Vaidya, PhD Student, Department of Internal Medicine and Clinical Nutrition, Institute of Medicine,

Sahlgrenska Academy at University of Gothenburg, Sweden;

${ }^{2}$ Umesh Raj Aryal, Assistant Professor, Department of Community Medicine,

Kathmandu Medical College, Kathmandu, Nepal;

${ }^{3}$ Andrej M Grjibovski, Professor, Department of International Public Health, Norwegian Institute of Public Health, Norway, and Director, International School of Public Health, Northern State Medical University, Arkhangelsk, Russia.

${ }^{4}$ Alexandra Krettek, Professor, Nordic School of Public Health NHV, Gothenburg, Sweden and Department of Internal Medicine and Clinical Nutrition, Institute of Medicine, Sahlgrenska Academy at University of Gothenburg, Sweden.

\section{Abstract}

Background: Primary open-angle glaucoma (POAG) is the commonest cause of irreversible blindness. Most hospitals in Nepal are carrying out opportunistic glaucoma screening for those attending hospitals for any eye consultation. However, there are no reports detailing the visual damage at the time of diagnosis confirming the early detection of cases.

Objectives: This study aimed to investigate the clinical features and visual status at the time of diagnosis of POAG in the Nepalese population.

Methods: We evaluated 173 newly diagnosed consecutive cases of POAG from three hospitals across Nepal. Glaucoma evaluation was carried out detailing the findings of visual acuity and visual fields. Continuous data were presented as means and standard deviations (SD) and categorical data as proportions ( $95 \% \mathrm{Cl})$. Unpaired t-tests compared continuous variables with $p$ value set at a $5 \%$ level of significance.

Results: Out of total patients, $82.1 \%$ were diagnosed incidentally while they visited the hospital for symptoms not expected to be for glaucoma. Only $9.8 \%$ of cases were aware of them being at risk of developing glaucoma and thus attended hospitals for regular check-up. Visual field examination revealed mean scores of mean deviation (MD) as low as $-13.24 \mathrm{~dB}$ and pattern standard deviation of $7.34 \mathrm{~dB}$. Glaucoma hemifield test was outside normal limits in $61.5 \%$ of eyes tested. Additionally, $4.7 \%$ patients were blind.

Conclusion: POAG cases presented late with significant visual damage. Existing opportunistic screening for glaucoma in Nepal needs to be combined with community-based glaucoma awareness programs to bring more people to hospital at the early stage of the disease.

Key words: Blindness, Intraocular pressure, Primary open-angle glaucoma, Visual acuity, Visual fields

\section{INTRODUCTION}

$\mathrm{G}$ laucoma is the second leading cause of blindness, outdistanced only by cataract ${ }^{1}$. Unlike cataract, it gives rise to irreversible blindness ${ }^{2,3}$. Primary open-angle glaucoma (POAG) is commonly seen globally including $\mathrm{Nepal}^{4-8}$. In 2010, almost 45 million people were affected by POAG worldwide; of these, 4.5 million (10\%) likely

\section{Address for correspondence}

Suraj Shakya-Vaidya

PhD Student

Department of Internal Medicine and Clinical Nutrition,

Institute of Medicine, Sahlgrenska Academy at University of Gothenburg, Sweden

E-mail: suraj.shakya-vaidya@gu.se were blind ${ }^{9}$. Various risk factors for POAG include intraocular pressure (IOP), myopia, age, race, genetic factors, hypertension, and diabetes ${ }^{10-13}$.

Indeed, POAG is often called "the silent thief of vision" because the disease lacks alarming symptoms ${ }^{14}$. Unaware of their clinical problem, afflicted individuals do not seek medical advice until the vision is severed or the visual loss is detected accidentally. Therefore, it is crucial that glaucoma screening be conducted regularly to help manage the condition at the earliest.

Eye care in Nepal focuses on carrying out screening programmes for glaucoma in the eye out-patient 
departments (OPD) and during surveys or mobile camps with the goal to detect glaucoma (especially POAG) at an early stage so as to prevent blindness $s^{6,15}$. However, reports demonstrating the visual status at presentation are scarce ${ }^{8}$ and no reports are available on detailed visual field damage at the time of diagnosis. It is of paramount importance to know the visual status of POAG at diagnosis and as this would suggest us whether the goal of detecting POAG at an early stage has been achieved. The present study aimed to investigate the presenting clinical features and visual status of POAG at the time of diagnosis.

\section{METHODS}

This descriptive study aimed to evaluate the clinical presentation and visual status of newly diagnosed cases of POAG presenting to the hospitals. We included POAG participants who were enrolled as 'cases' in our previous case-control study ${ }^{13}$ where we computed the sample size after reviewing several published data on the association of diabetes and hypertension with POAG ${ }^{16-18}$. However, we used the proportion of hypertension in control groups ${ }^{17}$, which was 0.12 , with an odds ratio (OR) of 2.4, and we assumed that correlation between cases and controls was $0.225^{19}$ which allowed us to obtain a sample size of a minimum of 168 cases. We determined the sample size with power of $90 \%$ at a $95 \%$ confidence interval. POAG cases were enrolled usinga consecutive non-random sampling technique.

We carried out this study in three hospitals located in central (Kathmandu), western (Pokhara) and far-western (Dhangadhi) regions of Nepal. Study centres were Nepal Medical College and Teaching Hospital, Geta Eye Hospital and Himalaya Eye Hospital.

This study covered adults ( $\geq 15$ years) with newly diagnosed POAG from our earlier study ${ }^{13}$. We included this age group because there are no reports from Nepal that indicate a minimum age for onset of POAG. Chronic illnesses are known to occur early in life before clinical manifestations appear ${ }^{20}$ which often become apparent only after decades ${ }^{20}$. As POAG is a chronic disease, we anticipated this disease to occur in younger age groups and wanted to determine the minimum age distribution of the disease. Nepal being a multiethnic society, also has a distinct pattern of distribution of different ethnic populations in the regions where the study was performed. We therefore enrolled participants belonging to ethnic groups such as Newars, Brahmins, Gurungs, and Tharus.

\section{INCLUSION AND EXCLUSION CRITERIA}

We enrolled adults with newly diagnosed POAG belonging to the aforementioned ethnic groups during the study period of February 2010 to May 2011. We excluded individuals with secondary glaucoma, narrow angles, previous ocular surgeries, ocular pathologies that obscure the view of the optic nerve head, and pathologies that could alter intraocular pressure (e.g. uveitis and high refractive errors $>5$ dioptre and astigmatism).

\section{ENROLMENT PROCESS}

Adult patients attending general eye OPDs were referred to the glaucoma clinic for glaucoma evaluation, if they were suspected to have POAG on the basis of (1) large cup to disc ratio (CDR) $>0.4$, (2) asymmetry of cup to disc ratio $>0.2$ in two eyes, (3) intraocular pressure (IOP) $\geq 23 \mathrm{~mm} \mathrm{Hg}$ and/or (4) gave strong family history of glaucoma. Those confirmed to have POAG were enrolled in the study.

\section{GLAUCOMA EVALUATION}

A pre-designed questionnaire was administered by a trained interviewer to collect clinical history including questions relating to reason for hospital visit, symptoms, present and past illness and medical history. Presenting visual acuity for distance and near (with existing optical correction if any) was assessed by ophthalmic assistants using internally illuminated Snellen's vision chart. Optometrist performed retinoscopy and subjective refraction for participants whose presenting visual acuity was less than $6 / 6$ in either eye.

Next, an Ophthalmologist performed a detailed evaluation of the anterior and posterior segment using Haag-Streit slit lamp and fundus biomicroscopy was performed with a +90 Dioptre (D) lens at $\times 16$ magnification to evaluate the optic disc. The pupils were dilated using $1 \%$ tropicamide and $2.5 \%$ phenylephrine, only if the view of the fundus was not satisfactory due to small pupil $<3 \mathrm{~mm}$ diameter ${ }^{21}$. The vertical cup-to-disc ratio (VCDR) was measured as the parameter to assess structural glaucomatous change. The margins of the cup were identified by viewing the point of maximum inflection of the vessels crossing the neuro-retinal rim. The vertical dimensions of the disc and cup were measured using a continuously adjustable vertical light beam and a scale calibrated in millimetres; diameters were then multiplied by magnification correction factor 1.33 for $+90 \mathrm{D} \mathrm{lens}^{22}$. Any notching, disc haemorrhage, peripapillary changes and retinal nerve fibre layer defects were recorded. 
Intraocular pressure was measured using Goldmann applanation tonometer, for three times in succession for each eye and an average of three measurements was used for data analysis. Gonioscopy was performed using Goldmann 3-mirror contact lens and visual fields were tested using static automated, white-on-white perimeter (Humphrey Field Analyser, Carl Zeiss Meditec, Germany) with correcting lens for refractive error. To ensure uniformity and prevent examination error and bias, a full threshold 24-2 program was applied which was routinely used in all the three hospitals. The visual field test was repeated when the patient reliability index was unsatisfactory (i.e., fixation loss > $20 \%$ and/or false positive and false negative indices exceeding 33\%) or glaucoma hemifield test (GHT) result was outside normal limits.

\section{DIAGNOSTIC CRITERIA}

In accordance with a modified Shaffer's classification, we labelled the angle of the anterior chamber as 'open angle' when we observed a grade III or grade IV angle ${ }^{23}$.

Intraocular pressure $\geq 23 \mathrm{mmHg}$ was considered high and $<23 \mathrm{~mm} \mathrm{Hg}$ was considered within normal range ${ }^{24}$. The minimum criteria for diagnosis of compatible glaucoma visual field defect was considered as a GHT outside normal limits together with a cluster of four or more contiguous points with $\mathrm{p}<5 \%$ on the pattern standard deviation plot (PSD) not crossing the horizontal meridian ${ }^{25}$.

Confirmation of glaucoma diagnosis was made on the basis of signs of structural damage of optic disc and compatible glaucomatous visual field defect, with raised intraocular pressure at least in one eye ${ }^{26}$. Diagnosis of POAG without visual field changes were made only when CDR was $\geq 0.7$ with IOP $>30 \mathrm{mmHg}$.

\section{DATA ANALYSIS}

We present continuous data as means and standard deviations (SD) and categorical data as proportions (95\% $\mathrm{Cl})$. We used unpaired t-tests to compare continuous variables and $\mathrm{p}$ value set at $5 \%$ level of significance. Statistical analysis was conducted using SPSS software, version 17.

\section{ETHICAL APPROVAL AND CONSENT}

The Nepal Health Research Council approved this study. All study participants were informed about the study and its purpose and were given a detailed explanation of the examination procedure. All participants gave informed consent. We also explained that participants could withdraw from the study at any time. POAG patients were treated with either anti-glaucoma medication or filtering surgery. Participants who could not afford treatment were treated free of cost at the participating hospitals.

\section{RESULTS}

\section{DEMOGRAPHIC FEATURES OF POAG PATIENTS}

Table 1 demonstrates the demographic features of 173 POAG patients enrolled in the study. Out of 173 participants, $71.1 \%$ were male and $28.9 \%$ were female. Regarding ethnicity distribution, Brahmins constituted 27.7\%, Newars 31.2\%, Gurungs $24.9 \%$ and Tharus were $16.2 \%$. Over $70 \%$ of participants with POAG were between 36 to 75 years of age. Though this study has chosen to enrol all participants $\geq 15$ years with POAG, there was only one participant who was under 30 years of age and rest were $>30$ years (Table 1 ).

\section{REASON FOR ATTENDING HOSPITAL}

Among all POAG patients, $60.7 \%$ visited the hospital for either vision-related symptoms or other unspecific symptoms related to eyes. Only $9.8 \%$ came for regular glaucoma evaluation as they were suspected to have glaucoma earlier and/or had a positive family history of glaucoma (Table 2).

\section{CLINICAL FEATURES Symptoms:}

Table 3 illustrates the clinical symptoms of the study participants. The most common symptom was blurred near vision accounting for $82.7 \%$. Some participants even came with diminished side vision (9.2\%).

\section{VCDR and IOP:}

Mean IOP was $27.9(\mathrm{SD}=3.15) \mathrm{mmHg}$ in males and 26.7 $(\mathrm{SD}=3.89) \mathrm{mmHg}$ in females $(\mathrm{p}=0.998)$. Mean VCDR in males and females was $0.7(\mathrm{SD}=0.18)$ and $0.6(\mathrm{SD}=0.21)$, respectively (Table 3 ).

\section{Visual fields:}

Table 4 shows the mean scores of global indices and GHT results. The mean of mean deviation (MD) that indicates an overall decibel value of each tested retinal point suggesting loss of visual field, was -13.24 (SD= -9.0). Mean corrected pattern standard deviation (CPSD), the corrected visual field pattern after deducting short term fluctuation (SF) was 6.65 (SD=4.2). We specifically looked for visual field defect patterns of 16 patients who came with subjective visual field loss so as to see 
whether their complaints were corresponding with the findings. All thirty two eyes of 16 POAG patients revealed severe loss of peripheral visual fields sparing just the central 20-30 degree. In rest of the patients, commonly seen visual field defect were arcuate defect, nasal step defect, paracentral defect within 10-20 degree field and generalized peripheral constriction of visual field. Among total eyes undergoing the visual field tests, $61.5 \%$ revealed GHT outside normal limits. Visual field results of nine $(2.8 \%)$ eyes of five patients (two eyes of four and a single eye of one patient) were not incorporated in this report due to an unsatisfactory reliability index despite a repeated test. The visual field test could not be carried out in $7.5 \%$ of total eyes due to visual acuity $<6 / 60$ and/ or loss of central vision.

\section{Visual acuity:}

Table 5 illustrates the severity of visual acuity as classified by the International Council of Ophthalmology ${ }^{27}$. We analysed the best corrected vision in the better eye. Among total eyes, $6.9 \%$ had moderate visual impairment, $2.9 \%$ had severe visual impairment and $4.7 \%$ were legally blind.

Table 1: Demographic and clinical characteristics of POAG cases

\begin{tabular}{|lcc}
\hline Variables & Number of Patients & Percentage $\mathbf{( 9 5 \% ~ C l )}$ \\
Gender & 123 & $71.1(64.4 ; 77.8)$ \\
Men & 50 & $28.9(22.2 ; 35.6)$ \\
Women & & \\
Ethnicity & 48 & $27.7(21.0 ; 34.3)$ \\
Brahmin & 54 & $31.2(24.3 ; 38.1)$ \\
Newar & 43 & $24.9(18.5 ; 31.3)$ \\
Gurung & 28 & $16.2(10.7 ; 21.7)$ \\
Tharu & & \\
Age group & 13 & $7.5(3.6 ; 11.4)$ \\
$* 15-35$ years & 55 & $31.8(24.9 ; 38.7)$ \\
$36-55$ years & 82 & $47.4(39.9 ; 54.8)$ \\
$56-75$ years & 23 & $13.3(8.2 ; 18.4)$ \\
\hline 75 years & $\mathbf{5 8 . 9 ( 1 4 . 4 )}$ & \\
\hline Mean age (SD) & & \\
\hline
\end{tabular}

*Only one patient in this group was under 30 years

Table 2: Reasons for attending eye outpatient department

\begin{tabular}{lcc}
\hline Reason & Number & Percentage \\
Have eye problems (symptoms) & 105 & $60.7^{*}$ \\
\hline Accompanying family member to hospital, so taking opportunity & 37 & $21.4^{*}$ \\
\hline Came for regular check-up (family history of glaucoma) & 17 & 9.8 \\
Referred by physician & 14 & 8.1 \\
\hline Total & $\mathbf{1 7 3}$ & $\mathbf{1 0 0 . 0}$ \\
\hline
\end{tabular}

*These cases were detected incidentally 
Table 3: Clinical features of POAG patients

\begin{tabular}{lcc}
\hline Clinical parameter & Number of Patients & Percentage $(\mathbf{9 5} \% \mathbf{C l})$ \\
Vision-related symptoms* & & \\
Blurred near vision & 143 & $82.7(77.2 ; 88.3)$ \\
Diminished distance vision & 36 & $20.8(14.6 ; 26.9)$ \\
Loss of side vision & 16 & $9.2(4.9 ; 13.5)$ \\
Symptoms unrelated to vision & & $40.5(33.2 ; 47.8)$ \\
Headache & 70 & $24.3(17.9 ; 30.7)$ \\
Ocular pain & 42 & $13.8(8.7 ; 18.9)$ \\
Watering & 24 & $12.1(7.2 ; 16.9)$ \\
Itching & 21 & $10.4(5.8 ; 14.9)$ \\
Redness & 18 & $10.9(6.3 ; 15.5)$ \\
Others & 19 & $\mathbf{p}$ value \\
VCDR* & Mean (SD) & $\mathrm{p}=0.999$ \\
Men & $0.7(0.18)$ & $\mathrm{p}=0.998$ \\
Women & $0.6(0.21)$ & \\
\hline IOP*** & & \\
Men & $27.9(3.15) \mathrm{mmHg}$ & \\
Women & $26.7(3.89) \mathrm{mmHg}$ & \\
\hline
\end{tabular}

*Each person had more than one symptom

** Vertical cup-to-disc ratio ***Intraocular pressure \# Unpaired t-test

Table 4: Visual field changes: Global indices and Glaucoma hemifield test

\begin{tabular}{|c|c|c|c|}
\hline Global Indices & \multicolumn{3}{|c|}{ Mean in dB (SD) } \\
\hline Mean deviation (MD) & \multicolumn{3}{|c|}{$-13.24(-9.0)$} \\
\hline Pattern standard deviation (PSD) & \multicolumn{3}{|c|}{$7.34(2.8)$} \\
\hline Short-term fluctuation (SF) & \multicolumn{3}{|c|}{$2.52(0.9)$} \\
\hline Corrected pattern standard deviation (CPSD) & \multicolumn{3}{|c|}{$6.65(4.2)$} \\
\hline Glaucoma Hemi-field Test & \multicolumn{3}{|c|}{ Number of eyes (\%) } \\
\hline Outside normal limit & \multicolumn{3}{|c|}{$197(61.5)$} \\
\hline Borderline & \multicolumn{3}{|c|}{$59(18.4)$} \\
\hline Generalized reduction in sensitivity & \multicolumn{3}{|c|}{$17(5.4)$} \\
\hline Within normal limit & \multicolumn{3}{|c|}{$38(11.9)$} \\
\hline *Unsatisfactory reliability index & \multicolumn{3}{|c|}{$9(2.8)$} \\
\hline Total eyes tested & \multicolumn{3}{|c|}{$320(100)$} \\
\hline \#End-stage disease (HFA not done) & \multicolumn{3}{|c|}{$26(7.5 \%)$} \\
\hline \multicolumn{4}{|c|}{$\begin{array}{l}\text { *Test result was not reliable even after repetition, so not considered for evaluation. } \\
\text { \#Unable to perform HFA due to loss of central vision and visual acuity< } 6 / 60 \text {. }\end{array}$} \\
\hline Range of visual acuity & Number of Cases & Percentage & $95 \% \mathrm{Cl}$ \\
\hline 6/6-6/18 (Mild/normal vision) & 148 & 85.5 & $80.3 ; 90.8$ \\
\hline 6/24-6/60 (Moderate visual impairment) & 12 & 6.9 & $3.1 ; 10.6$ \\
\hline 5/60-3/60 (Severe visual impairment) & 5 & 2.9 & $0.4 ; 5.4$ \\
\hline 2/60-NPL or visual field $<10^{\circ}$ (Legally blind) & 8 & 4.7 & $1.5 ; 7.8$ \\
\hline Total & 173 & 100.0 & \\
\hline
\end{tabular}




\section{DISCUSSION}

Although there were almost equal number of males and females attending the hospitals during the study period, the frequency of POAG was seen 2.5-fold higher in males as compared to females. There are some studies that show men being affected more frequently than their counterparts by POAG whereas others show no statistical difference between men and women ${ }^{10,28,29}$. One reason for having significantly higher number of men with POAG in our study could be addressed by the fact that women in Nepal utilize the health services less frequently than men $^{30}$. Our result suggests that the frequency of POAG could rise in people aged 35 years and above because over $70 \%$ of POAG cases in our study belonged to the 36 75 years age group showing increasing pattern with age. Earlier reports reveal a similar pattern of occurrence of POAG that rises with age ${ }^{10,28}$. Nonetheless, we had fewer cases of POAG $>75$ years of age which could probably be explained by low average life expectancy in $\mathrm{Nepal}^{31}$.

Current glaucoma screening in Asia relies on patients who come to hospital for other ocular complaints ${ }^{26}$ which was reflected in our study as well. A majority of people visited the hospital for eye problems related mostly to vision and other non-specific symptoms. Interestingly, $21.4 \%$ of our participants had their eyes tested while accompanying a family member to the hospital even though they had no eye problems. This finding suggests that such people would easily have missed the opportunity for an eye examination. Therefore, periodic and general eye examinations are crucial for asymptomatic individuals as well, especially if they belong to a high-risk category ${ }^{32}$. However, such examinations are feasible only if the population is aware of POAG and does not rely solely on symptoms to seek care.

Only $9.8 \%$ of total patients in our study came to hospital for periodic glaucoma test as they were either suspected to have glaucoma during their earlier visits to hospital and/or had a positive family history of glaucoma. A smaller proportion of people coming to hospital for regular glaucoma test may indicate poor awareness of glaucoma or barriers to seeking health care in the community. This finding is not surprising for a country like Nepal which lacks a national health screening policy unlike many high income nations $s^{33,34}$ where people are brought to hospital for regular checkups. Additionally, Nepal also lacks National Health Insurance policy that covers the cost of health care, preventing high out-ofpocket payments that are often the cause for not seeking health care in $\mathrm{Nepal}^{35}$.
Realizing the need for a health insurance policy, the Government of Nepal has drafted a policy for health insurance but is still at trial phase ${ }^{35}$. Patients referred by physicians were just $8.1 \%$, which is a low number given the rising burden of non-communicable diseases in $\mathrm{Nepal}^{36}$. There is increasing prevalence of both hypertension and diabetes, which may often associate with retinopathies and glaucoma ${ }^{13}$. We should have been seeing more referrals from general physicians but the referral system has not yet improved in Nepal. Poor referrals to hospitals have also been reported earlier ${ }^{37}$.

Often a case of POAG is detected accidentally while patients present to hospitals with some other unspecific symptoms or for a simple eye test for glass prescription because of its asymptomatic nature till the very end stage of the disease $\mathrm{e}^{38}$. This was clearly reflected in our study that revealed $82.7 \%$ of POAG cases presented to hospital with difficulty in near vision. Another tertiary hospital in Nepal reports similar findings among newly diagnosed POAG patients presenting to hospital eye $\mathrm{OPD}^{8}$. This finding was not unexpected as large proportions of our participants were $\geq 40$ years of age and would need glasses for presbyopia. Only $20.8 \%$ of our participants complained of diminished distance vision. This is normal because POAG spares central vision until the late stage of the disease. Thus, POAG patients usually have good distance vision and often do not notice a decline of peripheral vision ${ }^{14}$. Remarkably, $9.2 \%$ of POAG patients in this study complained about decreased side vision indicating peripheral visual field loss which was later confirmed by visual field testing that revealed a significant loss of peripheral visual field. Furthermore, $40.5 \%$ of our participants complained of headache and $24.3 \%$ had eye pain. These could have been early symptoms of POAG ${ }^{38}$ but they are mostly overlooked during hospital visits because headaches and ocular pain can result from many other conditions ${ }^{39}$ e.g. tiredness and migraine or cluster headaches.

According to the American Academy of Ophthalmology, the inclusion of glaucoma screening in a comprehensive adult eye evaluation is the most effective way of diagnosing glaucoma, especially for high-risk individuals and patients older than 40 years of age $\mathrm{e}^{40}$. Our study detected POAG mostly in patients who are 35 years and above, suggesting that every adult $\geq 35$ years attending the eye OPDs should have an opportunity for glaucoma screening, irrespective of their symptoms.

Although mean VCDR and mean IOP were slightly higher among males, they were not statistically significant. 
Earlier reports also show similar non-significant differences of mean IOP and VCDR among males and females ${ }^{41,42}$. The mean of MD in our study showed that the decibel value of the retinal threshold decreased to as lowas-13.24 (SD=-9.0) dB, which suggests a considerable overall visual field loss. Usually, an MD of $-2.00 \mathrm{~dB}$ or less suggests glaucoma ${ }^{43}$. Our finding therefore agrees with earlier reports ${ }^{21,44}$. The mean PSD was $7.34(S D=2.8) d B$, suggesting variability in the patients' response or actual visual field abnormality ${ }^{43}$. We excluded variability in patients' response by assessing the mean CPSD, which was $6.65(S D=4.2) d B$. This CPSD value represents an irregular visual field pattern resulting from actual field loss after deducting the SF or variability of the patient's response to the test ${ }^{43}$. In this study, mean SF was 2.52 $(\mathrm{SD}=0.9)$, which is marginally higher compared with other studies ${ }^{21,44}$. However, the mean CSPD in our study was similar to that reported earlier ${ }^{21,45}$. Among POAG patients undergoing a visual field test, $61.5 \%$ showed GHT outside normal limits. Although, visual fields of 38 eyes $(11.9 \%)$ were within the normal limits, they were diagnosed as POAG on the basis of a large VCDR $(\geq 0.7)$ and IOP higher than $30 \mathrm{mmHg}$, which means that POAG was detected before any visual field changes occurred. In this respect, our results disagree with an Indian study ${ }^{46}$ that reported $75 \%$ of eyes outside normal limits and $25 \%$ with either borderline or generalized reduction of sensitivity. This difference could be due to the fact that our study was conducted among those who came to hospital for general eye problems and were screened for glaucoma; as a result they may have been identified at an earlier stage of the disease. Of total eyes with POAG, $7.5 \%$ could not be considered for a visual field test due to poor vision or loss of central vision concurring with the result originating from India ${ }^{46}$. With the finding of mean MD as low as $-13.24 \mathrm{~dB}$, the mean PSD $7.34 \mathrm{~dB}$ and $61.5 \%$ of total eyes having GHT outside the normal limits indicated that most POAG participants already had moderate to severe damage in their visual fields when diagnosed for the first time.

In our study, $85.5 \%$ of POAG participants had normal to mild visual impairment. This finding is not unusual because most POAG patients do not recognize peripheral visual field damage until they lose their central field of vision, which often remains intact until end-stage POAG. Additionally, $4.7 \%$ of our participants were legally blind at the time of diagnosis. Although this proportion is small, it could have a substantial impact on the prevalence of blindness. Extrapolating this number in relation to the adult population older than 30 years of age in Nepal (44.9\%, or 13.6 million) ${ }^{47}$ and considering the lowest POAG prevalence $(3.25 \%)^{13}$, suggests that POAG affects 443,607 people in Nepal. If $4.7 \%$ are likely to become blind, 20,849 people could become irreversibly blind just due to POAG.

\section{LIMITATIONS}

To maintain uniformity of examination procedures in our study, we left out some of the standard glaucoma evaluations. Since not all participating hospitals had Pachymeter, we chose not to measure central corneal thickness which may have affected the interpretation of IOP. However IOP was not considered as main diagnostic parameter in our study. Only smaller proportion of cases was diagnosed just on the basis of large CDR $\geq 0.7$ and IOP higher than $30 \mathrm{mmHg}$ without compatible visual field defect. We tested visual fields using the full-threshold 24-2 program instead of the SITA Standard, as one of the hospitals was not using this program. Therefore, the patient fatigue component may have affected the visual fields to some extent, however, we repeated the visual fields when the reliability index was unsatisfactory and glaucoma hemifield test was outside normal limits. Furthermore, our sample size is limited and this study may not be representative of whole Nepal.

\section{CONCLUSION}

POAG is more commonly seen among men and after the age of 35 years. Most POAG cases were detected accidentally at late stage with moderate to severe visual field damage at the time of diagnosis. Additionally, $7.5 \%$ of totaleyes with POAG had end-stage visual field damage. Further, $4.7 \%$ of total patients were legally blind upon initial diagnosis, with vision $<3 / 60$ in both eyes.

Therefore, this study suggests that existing screening programs for glaucoma are helping to detect POAG cases but not earlier enough to prevent them from visual impairment and blindness. It also suggests that irrespective of symptoms, no adult over 35 years of age should leave the hospital without being screened for glaucoma. Community-based research should explore awareness regarding POAG and the depth of knowledge regarding its risk factors. Finally, community-based awareness programs should be introduced on the regular basis in addition to screening programs that are being carried out at hospitals to encourage more people to go to hospital as early as possible (i.e., before visual damage).

\section{ACKNOWLEDGEMENT}

This study was funded by the Wilhelm and Martina Lundgren's Foundation and Johan \& Jacob Söderberg's 
Foundation in Sweden. We thank Nepal Medical College Teaching Hospital, Kathmandu, Himalaya Eye Hospital, Pokhara and Geta Eye Hospital, Dhangadi, Nepal, for allowing us to conduct this study and for support at local level including free services to participants who were unable to afford such service. We thank scientific editor Karen Williams (Kwills Editing Services, Weymouth, MA, USA) for providing professional English-language editing of this article.

\section{REFERENCES}

1. Quigley HA, Browman AT. The number of people with glaucoma worldwide in 2010 and 2020. Br J Ophthalmol. 2006;90(3):262-7.

2. Roodhooft JMJ: Leading causes of blindness worldwide. Bull Soc Belge Ophtalmol. 2002;283:1925.

3. Thylefors B, Negrel AD. The global impact of glaucoma. Bull World Health Organ. 1994;72(3):3236.

4. Anton A, Andrada, M, Mujica V, Calle MA, Portela J, Mayo A. Prevalence of primary open angle glaucoma in a Spanish population: the Segovia study. J Glaucoma. 2004;13:371-6.

5. Friedman D, Wolfs $R$, O'Colmain B, Klein B, Taylor $\mathrm{H}$, West $\mathrm{S}$, et al. Prevalence of open-angle glaucoma among adults in the United States. Arch Ophthalmol. 2004;122(4):532-8.

6. Thapa SS, Paudyal I, Khanal S, Twyana SN, Paudyal G, Gurung R, et al. A population-based survey of the prevalence and types of glaucoma in Nepal: the Bhaktapur Glaucoma Study. Ophthalmology. 2012;119(4):759-64.

7. Sah RP, Badhu BP, Pokharel PK, Thakur SK, Das $H$, Panda A. Prevalence of glaucoma in Sunsari district of eastern Nepal. Kathmandu Univ Med J. 2007;5(3):343-8.

8. Paudyal I, Thapa SS, Paudyal G, Gurung R, Ruit S. Glaucoma at a tertiary referral eye hospital in Nepal. Nepal J Ophthalmol. 2011;3(6):123-7.

9. Johnson GJ, Minassian DC, Weale RA, West SK. The epidemiology of eye disease. 3rd ed. London, UK: Imperial College Press; 2012 May 13.

10. Rudnicka AR, Mt-Isa S, Owen CG, Cook DG, Ashby D. Variations in primary open-angle glaucoma prevalence by age, gender, and race: a Bayesian meta-analysis. Invest Ophthalmol Vis Sci. 2006;47(10):4254-61.

11. Mitchell P, Lee AJ, Rochtchina E, Wang JJ: Openangle glaucoma and systemic hypertension:

\section{AUTHOR CONTRIBUTIONS}

SSV participated in case examination and drafted the manuscript. URA was involved in data management and statistical evaluation. AMG assisted and reviewed tabulation, statistical evaluation and manuscript. AK assisted and reviewed all tabulation of data and evaluation, and participated in manuscript writing. All authors have read and approved the final manuscript.

Disclosure: Authors have no conflict of interest the blue mountains eye study. J Glaucoma. 2004;13(4):319-26.

12. Bonovas $\mathrm{S}$, Peponis V, Filioussi K: Diabetes mellitus as a risk factor for primary open angle glaucoma: a meta analysis. Diabetic Med. 2004;21(6):609-14.

13. Shakya-Vaidya S, Aryal UR, Upadhyay M, Krettek A. Do non-communicable diseases such as hypertension and diabetes associate with primary open-angle glaucoma? Insights from a case-control study in Nepal. Glob Health Action 2013;6:22636 http://dx.doi.org/10.3402/gha.v6i0.22636

14. Rao US. Diagnosing, preventing, and treating glaucoma. Virtual Mentor, American Medical Association Journal of Ethics. 2010;12(12):934-7.

15. Sarkar S, Mardin C, Henning A. Profile of the glaucoma and intervention in a large eye care centre in Southeast Nepal. Nepalese J Ophthalmol. 2010;2(1):3-9.

16. Tielsch JM, Katz J, Sommer A, Quigley HA, Javitt JC. Hypertension, perfusion pressure, and primary open-angle glaucoma: a population-based assessment. Arch Ophthalmol 1995;113(2):216-21.

17. Katz J, Sommer A. Risk factors for primary open angle glaucoma. Am J Prev Med. 1988;4(2):110-4.

18. Jonas JB, Grundler AE. Prevalence of diabetes mellitus and arterial hypertension in primary and secondary open-angle glaucomas. Graefes Arch Clin Exp Ophthalmol.1998;236(3):202-6.

19. Dupont WD. Power calculations for matched casecontrol studies. Biometrics. 1988;44(4):1157-68.

20. World Health Organization. Preventing chronic diseases: a vital investment. [Cited 2014 Aug 27]. Available from: http://www.who.int/chp/chronic_ disease_report/en.

21. Gazzard G, Foster PJ, Devereux JG, Oen F, Chew P, Khaw PT, et al. Intraocular pressure and visual field loss in primary angle closure and primary open angle glaucomas. Br J Ophthalmol. 2003;87(6):720-5.

22. Tsai JC. How to evaluate the suspicious optic disc. Rev Ophthalmol [Internet]. 2005 Jun 15 [cited 2013 
May 18]; 12(6):40-2. Available from: http://www. revophth.com/issue_toc/i/1315/

23. Stamper R, Lieberman M, Drake M. Becker-Shaffer's Diagnosis and Therapy of Glaucomas. 8th ed. UK: MOSBY an imprint of Elsevier Inc; 2009.

24. Tsai JC. High Eye Pressure and Glaucoma [Internet]. San Francisco: Gleams, Glaucoma Research Foundation; 2008 Jan [updated 2012 Apr 24; cited 2014 Jan 12]. Available from: http://www.glaucoma. org/gleams/high-eye-pressure-and-glaucoma.php

25. Foster PJ, Oen FT, Machin DS, Ng TP, Devereux JG, Johnson GJ et al. The prevalence of glaucoma in Chinese residents of Singapore: a cross-sectional population survey in Tanjong Pagar district. Arch Ophthalmol. 2000;118:1105-11

26. Sashidharan R, editor. Asia Pacific Glaucoma Guidelines 2008. 2nd ed. Sydney: South East Asia Glaucoma Interest Group; 2008. 108 p.

27. International Council of Ophthalmology. Visual standards, aspects and ranges of visual loss with emphasis on population surveys. 29th International Congress of Ophthalmology, Sydney, Australia. 2002 Apr.

28. Ramakrishnan R, NirmalanPK, Krishnadas R, Thulasiraj R, Tielsch JM, Katz J, et al. Glaucoma in a rural population of southern India: the Aravind Comprehensive Eye Survey. Ophthalmology. 2003;110(8):1484-90.

29. Dandona R, Dandona L, Naduvilath TJ, Nanda A, McCarty CA. Design of a population-based study of visual impairment in India: The Andhra Pradesh Eye Diseases Study. Indian J Ophthalmol. 1997;45(4):251-7.

30. Gender Equity in eye Health: Lessons from Eye Care. Policy Brief. Nepal: Nepal Gender and Eye Health Group; 2010. 7p.

31. Thapa S. The human development index: a portrait of the 75 districts in Nepal. Asia Pac Popul J. 1995;10(2):3-14.

32. Mohammed A. Patients and glaucoma: what are the challenges? Community Eye Health J. 2012;25(79, 80):44-5.

33. NHS Choices [internet]. London: Department of Health; Glaucoma-diagnosis; 2013 [cited 2013 June 12]; available from: http://www.nhs.uk/Conditions/ Glaucoma/Pages/Diagnosis.aspx

34. Holland WW, Stewart S, Masseria C. European Observatory on Health Systems and Policies; Policy Brief: Screening in Europe. Brussels, Belgium: WHO Regional Office for Europe; 2006. 8 p.

35. Ministry of Health and Population. National health insurance policy 2013 [Internet]. Kathmandu (NP): Ministry of Health and Population; 2013 [cited 2013
Oct 13].Available from: http://p4h-network.net/ wp-content/uploads/2013/10/2013_03_Nepal_ Health_Insurance_Policy_fin.pdf

36. Dhital SM, Karki A. Dealing with the burden of hypertension in Nepal: current status, challenges and health system issues. Regional Health Forum 2013;17(1):44-52.

37. Furber AS. Referral to hospital in Nepal: 4 years' experience in one rural district. Tropical Doctor. 32(2):75-8.

38. Fazio D. What are the symptoms of glaucoma? [Internet]. San Francisco: Gleams, Glaucoma Research Foundation; 2009 Sep [Updated 2012 Apr 24; cited 2014 Jan 14]. Available from:http://www. glaucoma.org/gleams/what-are-the-symptoms-ofglaucoma.php

39. Rasmussen BK, Jensen $R$, Schroll $M$, Olesen J.Epidemiology of headache in a general population--a prevalence study. J Clin Epidemiol.1991;44(11):1147-57.

40. American Academy of Ophthalmology. Glaucoma Panel. Primary open-angle glaucoma. Preferred practice pattern. San Francisco: American Academy of Ophthalmology;2000. p. 1-36.

41. Mohammed J, Taklikar RH, Taklikar A, Itagi V, Bennal A. Variation of intraocular pressure with age and gender. Natl J Physiol Pharm Pharmacol. 2014;4(1):57-60.

42. Khan IS, Ahmad M, Saeed N. Spectrum of optic disc changes in primary open angle glaucoma. J Postgrad Med Inst. 2014;28(1):87-92.

43. Kahook MY, Noecker RJ. How Do You Interpret a 24-2 Humphrey Visual Field Printout? Glaucoma Today. 2007 Nov;57-9.

44. Wang J-C, Gazzard G, Foster PJ, Devereux JG, Oen FTS, Chew PTK, Khaw PT, Seah SKL. Interocular asymmetry of visual field defects in primary open angle glaucoma and primary angle- closure glaucoma. Eye. 2004;18(4):365-8.

45. Rhee K, Kim YY, Nam DH, Jung HR. Comparison of visual fields between primary open angle glaucoma and chronic primary angle closure glaucoma in early or moderate stage of disease. Korean J Ophthalmol. 2001;15(1):27-31.

46. Kulkarni U. Early detection of primary open angle glaucoma: Is it happening? [Internet]. J Clin Diag Res. 2012 May [cited 2014 Jan 26];6:667-70. Available from:http://www.jcdr.net/article_fulltext. asp?issn=0973-709x\&year $=2012 \&$ month $=$ May\&vol ume $=6 \&$ issue $=4 \&$ page $=667 \&$ id $=2113$

47. World Fact Book. Nepal demographic profile 2013 [Internet]. Available from: http://www.indexmundi. com/nepal/demographics_profile.html 